\title{
Number of larval instars and sex-specific plasticity in the development of the small heath butterfly, Coenonympha pamphilus (Lepidoptera: Nymphalidae)
}

\author{
ENRIQUE GARCÍA-BARROS
}

Department of Biology (Zoology), Universidad Autónoma de Madrid, E-28049 Madrid, Spain; e-mail: garcia.barros@uam.es

Key words. Lepidoptera, butterfly, Satyrinae, Coenonympha, development, diapause, growth, head capsule, instar, moulting, phenotypic plasticity, seasonality

\begin{abstract}
The number of larval moults, larval head capsule width and pupal weight were investigated in both direct-developing and diapausing individuals of a South-West European population of Coenonympha pamphilus. The frequency distributions of head widths of successive larval instars overlapped, partly due to variation in the number of larval moults. The larvae that entered diapause went through five instars, instead of the four reported from this species. The evidence indicates that the five instar developmental pathway represents a plastic response rather than an example of compensatory growth. This alternative growth pattern was expressed in response to short photoperiods in parallel with, or as a consequence of, larval diapause. On average, the larvae with five instars had larger heads than their normal siblings. This resulted in comparatively heavier male pupae, while the opposite trend occurred in females. It is concluded that the variation in the number of larval instars is a plastic response to diapause when temperatures remain mild and that it might have an adaptive value in areas with mild winter climates. The sexually dimorphic expression in the larval growth patterns, in terms of pupal weight, may well imply different patterns of allocation of larval resources to adult structures, although sex-dependent differences in investment into purely larval structures cannot be discounted.
\end{abstract}

\section{INTRODUCTION}

Phenotypic plasticity in insect life histories provides a way of optimising phenotype to the environment, which may substantially contribute to individual fitness in seasonal habitats (Tauber \& Tauber, 1981; West-Eberhart, 1989; Nylin \& Gotthard, 1998). Recent studies on plastic responses in the phenology of butterfly life histories have often focused on three crucial traits, i.e. size, development time and growth rate (Nylin, 1994). Pupal weight is often taken as a surrogate of adult body weight (e.g. Wiklund \& Solbreck, 1982; Nylin et al., 1993; Soontiëns \& Bink, 1997; Kemp, 2000). In addition, pupal weight is also an accurate expression of the total weight gain achieved by the larvae. This "composite" interpretation of the role of the pupal stage may mask some complex underlying relations, such as sex-linked differential investment of larval-gathered resources into adult structures (the more evident example of this being sexually dimorphic adult to pupal weight ratios). A further insight into plastic responses during the larval stage may be gained by using measurements of larval size that are independent of weight and show a variable response to environmental factors.

Head capsule width is one such trait because it provides a linear measurement of larval size that can be contrasted with pupal or adult sizes. In Lepidoptera (and other holometabolous insects with eruciform larvae), the larval head capsule is the most conspicuous fully sclerotized structure. Head capsule growth is basically restricted to the period of ecdysis and the head sizes of successive larval instars tend to follow a regular (often exponential) progression (Dyar, 1890). This regularity has been formalised in a number of ways and widely applied to identi- fying larval instars (e.g. Gargiullo \& Berisford, 1982; Fink, 1984). Such use is not efficient in all instances due to overlapping frequency distributions of the larval head widths of successive instars and variable number of instars (Gaines \& Campbell, 1935; Goettel \& Philogene, 1979). The causes of the variation in number of instars include genetic variation (e.g. Zhou \& Topp, 2000), diapause (Yin \& Chippendale, 1974), compensatory growth on poor quality substrates, sexual dimorphism, temperature, growth rates or even larval gregariousness (reviewed by Wigglesworth, 1972). Thus, variability in the number of larval instars may represent a plastic response to environmental factors, and provide a tool for identifying different potential developmental pathways, their causes and effects on adult size. Three points are of interest here: firstly, do additional larval instars result in larger final instar larvae (with a potential positive effect on pupal size), or just compensate for poor growth in early instars. Secondly, do the larger final instar larvae develop into larger pupae, or adults. Thirdly, to what extent do these effects differ between populations, sexes or generations and indicate different patterns of allocation of larval resources into adult soma.

One comparison of this kind was possible using material derived from a wider rearing experiment of a Mediterranean population of the small heath butterfly, Coenonympha pamphilus (L., 1758). This satyrine Nymphalid is widespread in the Western Palaearctic (Kudrna, 2002). The larvae feed on several grass species, the adults are on the wing in spring and summer, and produce one or more broods depending on latitude and altitude. The larvae of this species are reported to moult three times, hence undergoing four larval instars, and to hibernate in diapause in the third (penultimate) instar (Roos, 1978; 
Wickman et al., 1990). In a study of the larval phenology of this insect in Central Spain, a degree of heterogeneity in the weight of diapausing larvae was detected, throwing some doubt on the identity of the hibernating instar. Detailed data on the head widths and pupal weights of a number of individuals were recorded during this study, of both direct developing and diapausing larvae. This data proved interestingly that the number of instars is potentially variable in this species. Given this variation, the current study had two objectives. First, to determine the extent to which the presence of an extra instar was determined or induced by larval diapause. Second, and more interesting, to document whether the "one extra instar" developmental pathway represented the expression of a reaction norm involving sexually dimorphic patterns in the allocation of larval somatic materials in the pupae.

\section{MATERIALS AND METHODS}

Eggs were obtained from females collected at Manzanares el Real (province of Madrid, Spain: $40^{\circ} 43^{\prime} \mathrm{N}, 4^{\circ} 08^{\prime} \mathrm{W}, 900 \mathrm{~m}$ a.s.1.). The eggs were kept under standard conditions (temperature of $23 \pm 0.8^{\circ} \mathrm{C}$, photoperiod of $16 \mathrm{~L}: 8 \mathrm{D}$ ) until eclosion. The newly-hatched larvae were transferred to individual plastic jars (250 ml) containing a small amount of substrate (ca. $50 \mathrm{~cm}^{3}$ of garden soil) with grass growing in it. A commercial grass mixture of Festuca rubra and Poa annua was used as food. The grass was planted in large pots and transferred to the jars when it was ca. $10 \mathrm{~cm}$ height. The larvae were regularly transferred to new jars with fresh grass, and inspected periodically.

To measure the head width, the larvae were gently placed on a piece of filter paper in the bottom of a Petri dish softly illuminated. As soon as the larvae ceased moving, the maximum head width was measured from above. This was done to the nearest division of a micrometric grid incorporated in a binocular microscope $(1$ division $=0.035 \mathrm{~mm})$. Additional head widths of larvae of unknown instar were measured at other times in this study. Measuring the head capsules of living larvae made it possible to compare the linear measurements of all the larval instars: the head capsule widths of the last instar larvae cannot be measured using exuviae and those of the smallest larvae were often lost in the rearing jars. Fortunately, the larvae of this species are slow-moving, and can easily be managed in the way described above. A measurement error of at most 1-3 scale units (equivalent to $0.11 \mathrm{~mm}$ ) is assumed for the largest head capsules (this was not determined specifically). The pupae were weighed to the nearest $0.01 \mathrm{mg}$ within $24 \mathrm{~h}$ of pupation.

Collection data did not conform to an experimental design, since a variable number of instars was not a priori expected. Instead, the study is based on subsets of larvae that were collected and measured as described above. Fortunately, however, these included several subsets of larvae derived from the same females but reared under different conditions. Given that at most five eggs laid by each female were included in the same set and that the initial sizes of these were 40-50 eggs, the larval groups were treated as randomly selected and therefore any potential maternal effects can reasonably be ignored.

The larvae were reared either outdoors (natural temperature and photoperiod), or under controlled conditions (fixed photoperiod and temperature). Both rearing protocols were such that some part of the larvae exhibited diapause and others developed directly. Outdoor rearing was carried out on the Campus of the Universidad Autónoma de Madrid, and included larvae from eggs hatched during late April and early May (of which all the larvae developed into adults in summer), and larvae born in the

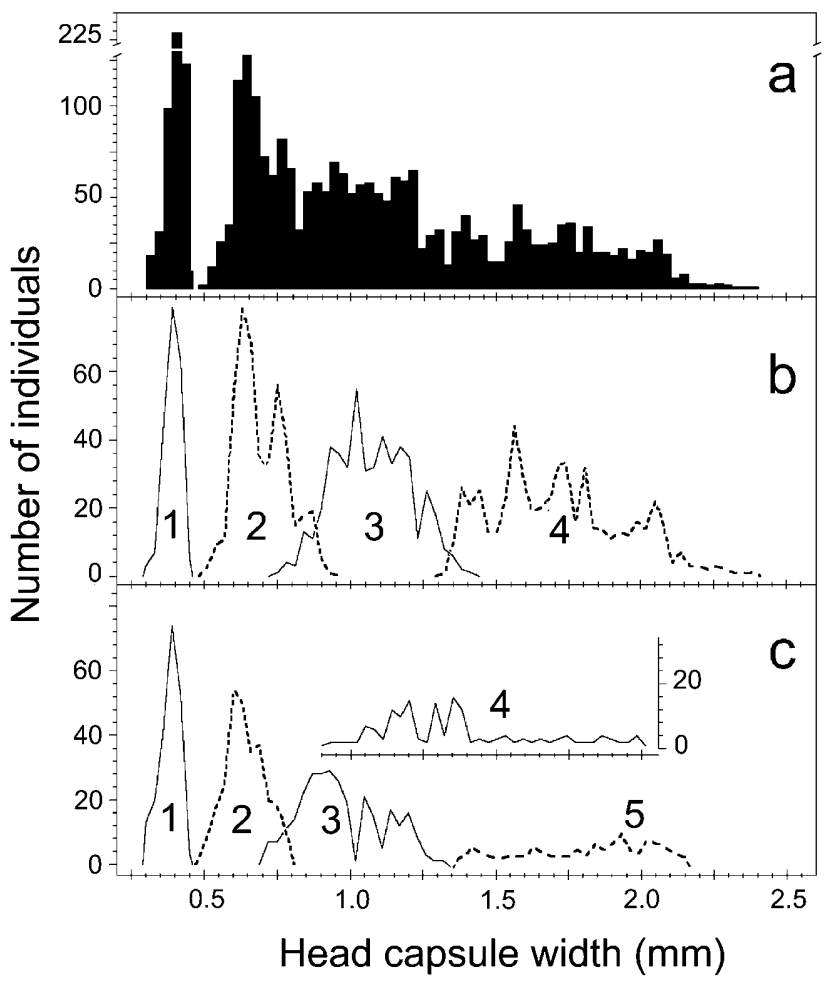

Fig. 1. Frequency distribution of the head capsule widths of larval Coenonympha pamphilus reared in the laboratory under different conditions (number of individuals on the $\mathrm{Y}$ axis): $\mathrm{a}=$ all available measurements, $\mathrm{b}=$ larvae with four instars, $\mathrm{c}=$ larvae with five instars (head widths of the fourth instar individuals of this group are shown separately). Note that the sample size in a is larger than in $b+c$.

first half of August, which entered winter diapause and with few exceptions pupated the next spring. Controlled laboratory rearing was done in environmental cabinets at a constant temperature of $23^{\circ} \mathrm{C}\left( \pm 0.8^{\circ} \mathrm{C}\right)$ constant temperature, and photoperiods of $16 \mathrm{~L}: 8 \mathrm{D}$ (direct development), 14L : 10D and 13L : 11D. The majority of the larvae of C. pamphilus from this population enter diapause at day lengths of $14 \mathrm{~h}$ or less (unpubl.). Given the relatively small sample sizes, the two last groups $(14 \mathrm{~L}$ and $11 \mathrm{~L})$ were treated as the same sample. Diapausing larvae were transferred to a $16 \mathrm{~L}: 8 \mathrm{D}$ photoperiod after more than 40 days in diapause in order to induce the completion of larval development and pupation. Larval diapause continued under this high temperature $\left(23^{\circ} \mathrm{C}\right)$ for as long as would normally be expected under field conditions in winter. This may be one reason why some part of the larvae kept in these conditions failed to pupate, which also reduced sample sizes. Only individuals that successfully developed to the adult stage were used for detailed comparisons, although the data from a few more individuals that pupated but were lost before reaching the adult stage were incorporated for comparisons where sex was not involved.

\section{RESULTS}

\section{Number of larval instars}

The frequency distribution of larval head capsule widths collected during this study (all available measurements) is shown in Fig. 1. Apart from the neat peak for the first instar and, to some extent, the second and third instars, there were no clear-cut discrete size classes (Fig. 
TABLE 1. Average maximum head widths (in $\mathrm{mm}$ ) for all the larvae with four and five larval instars (s.d.= standard deviation, $\mathrm{n}=$ sample size; total $\mathrm{n}$ varies between instars due to the addition of some data for larvae with a known number of instars but for which not all instars were measured).

\begin{tabular}{ccccccccc}
\hline \multirow{2}{*}{ Instar } & \multicolumn{3}{c}{ Larvae with 4 instars } & & \multicolumn{3}{c}{ Larvae with 5 instars } \\
\cline { 2 - 3 } \cline { 7 - 8 } & Mean & s.d. & $\mathrm{n}$ & & Mean & s.d. & $\mathrm{n}$ \\
\hline 1 & 0.382 & 0.031 & 305 & & 0.386 & 0.062 & 107 \\
2 & 0.691 & 0.094 & 457 & & 0.638 & 0.062 & 107 \\
3 & 1.084 & 0.144 & 493 & & 0.928 & 0.106 & 117 \\
4 & 1.704 & 0.242 & 498 & & 1.336 & 0.239 & 109 \\
5 & - & - & - & & 1.867 & 0.276 & 84 \\
\hline
\end{tabular}

1a). An inspection of the individual growth histories demonstrated that some of the larvae had undergone four instars, while others underwent one further (fifth) instar. Even when the two groups were plotted separately (Fig. 1) a degree of overlap between the size ranges of successive instars remained. In the larvae with five instars, this was true for the three last instars. There were no significant differences between the mean head capsule width of the first instar of both groups $\left(\mathrm{F}_{1,401}=0.22, \mathrm{P}=0.64\right)$, while that of second instar larvae that underwent five instars was smaller than that of larvae with four instars $\left(\mathrm{F}_{1,401}=12.46, \mathrm{P}=0.0005\right)$ (Table 1$)$.

The average head width growth relative to instar number was consistent within each group of larvae (Fig. 2). Larvae with five instars had a lower rate of head growth relative to instar number, since the slopes of the regression lines (head width on instar number, Fig. 2) were significantly different (respectively 0.21 and 0.17 ; ANCOVA, $\mathrm{F}=322.2, \mathrm{P}<0.0001$, d.f. $=1$ ). On average, the larvae that went through five instars had a larger final instar head capsule width than the larvae with four instars

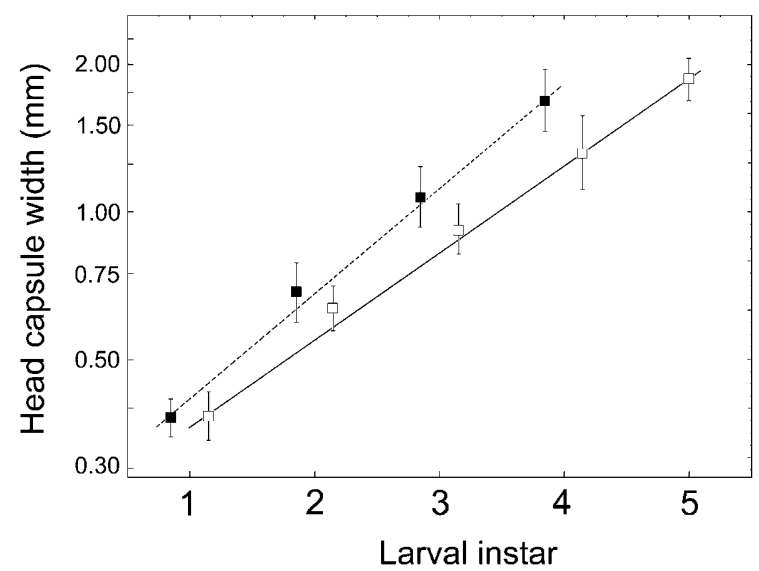

Fig. 2. Relationship between mean larval head width and instar for larvae with four (solid squares, dashed line) and five instars (empty squares, solid line). Vertical bars represent \pm 1 standard deviation; head widths were log-transformed. The regression lines and statistics (calculated using the instar average in each of the two subsets) are: four instars, $\log _{10}$ head width $=-0.616+0.214$ (instar number) $(\mathrm{r}=0.998, \mathrm{P}=0.002, \mathrm{n}$ $=4$ ); five instars, $\log _{10}$ head width $=-0.558+0.160$ (instar number $)(\mathrm{r}=0.996, \mathrm{P}=0.0002, \mathrm{n}=5)$.
TABLE 2. Relationships between the successive larval head sizes of individual larvae, and between larval head width and pupal size, measured as correlations (Pearson $r$ values) for larvae with four and five instars. Sample sizes as in Table 1. L1 to $\mathrm{L} 5=$ first to fifth larval instars. $* * *=\mathrm{P}<0.001, * *=\mathrm{P}<$ $0.01, *=\mathrm{P}<0.05, \mathrm{~ns}=$ not significant (exact values given for non-significant relations where $\mathrm{P}$ is close to 0.05 ). Note that there are only significant correlations between successive larval head widths in the latter instars (the head sizes of the intermediate and final instars were largely independent of first instar larval head widths), and that pupal weight was broadly independent of the head sizes of the first two larval instars (and weakly, or non significantly correlated with the penultimate and final instar head widths).

\begin{tabular}{|c|c|c|c|c|c|}
\hline & L2 & L3 & L4 & L5 & Pupal weight \\
\hline \multicolumn{6}{|c|}{ Four instars } \\
\hline L1 & $-0.12(\mathrm{~ns})$ & $-0.06(\mathrm{~ns})$ & $0.01(\mathrm{~ns})$ & - & $-0.04(\mathrm{~ns})$ \\
\hline L2 & & $0.59 * * *$ & $0.20 * *$ & - & $0.02(\mathrm{~ns})$ \\
\hline L3 & & & $0.50 * * *$ & - & $0.11(\mathrm{P}=0.07)$ \\
\hline L4 & & & & - & $0.30 * *$ \\
\hline \multicolumn{6}{|c|}{ Five instars } \\
\hline L1 & $-0.02(\mathrm{~ns})$ & $-0.03(\mathrm{~ns})$ & $0.04(\mathrm{~ns})$ & $0.03(\mathrm{~ns})$ & $0.12(\mathrm{~ns})$ \\
\hline L2 & & $0.50 * * *$ & $0.26^{*}$ & $0.17(\mathrm{~ns})$ & $-0.01(\mathrm{~ns})$ \\
\hline L3 & & & $0.56^{* * *}$ & $0.36^{* *}$ & $0.29 *$ \\
\hline L4 & & & & $0.29^{*}$ & $0.22(\mathrm{P}=0.07)$ \\
\hline L5 & & & & & $0.40 * *$ \\
\hline
\end{tabular}

(ANOVA, $\mathrm{F}_{1,341}=12.8, \mathrm{P}=0.0004$ ), even when the distribution ranges of the two groups in their final instar were roughly similar and the maximum values were recorded for larvae that had four instars (Fig. 1). The correlations between instar-specific head widths, as well as between these and pupal weight for the two groups of larvae are given in Table 2 .

\section{Number of instars, rearing conditions and sex}

Fifth instar larvae were detected only among those kept in conditions promoting diapause (test in the proportions

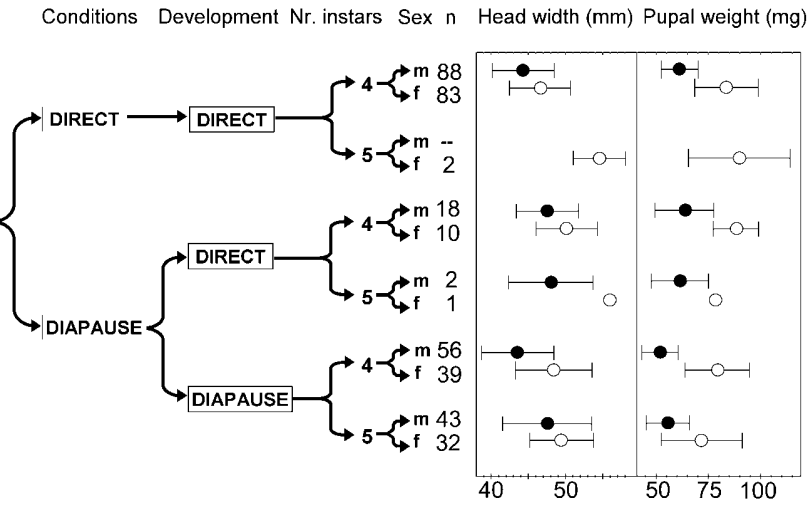

Fig. 3. Summary of the relations between the overall rearing conditions (conditions promoting either direct development or diapause), actual developmental pathway, number of instars, sex and sample size (n). Average last instar larval head width, and pupal weights for males (solid circles) and females (empty circles) are given together with bars indicating 95\% confidence ranges $(\mathrm{n}=$ sample size $)$. 


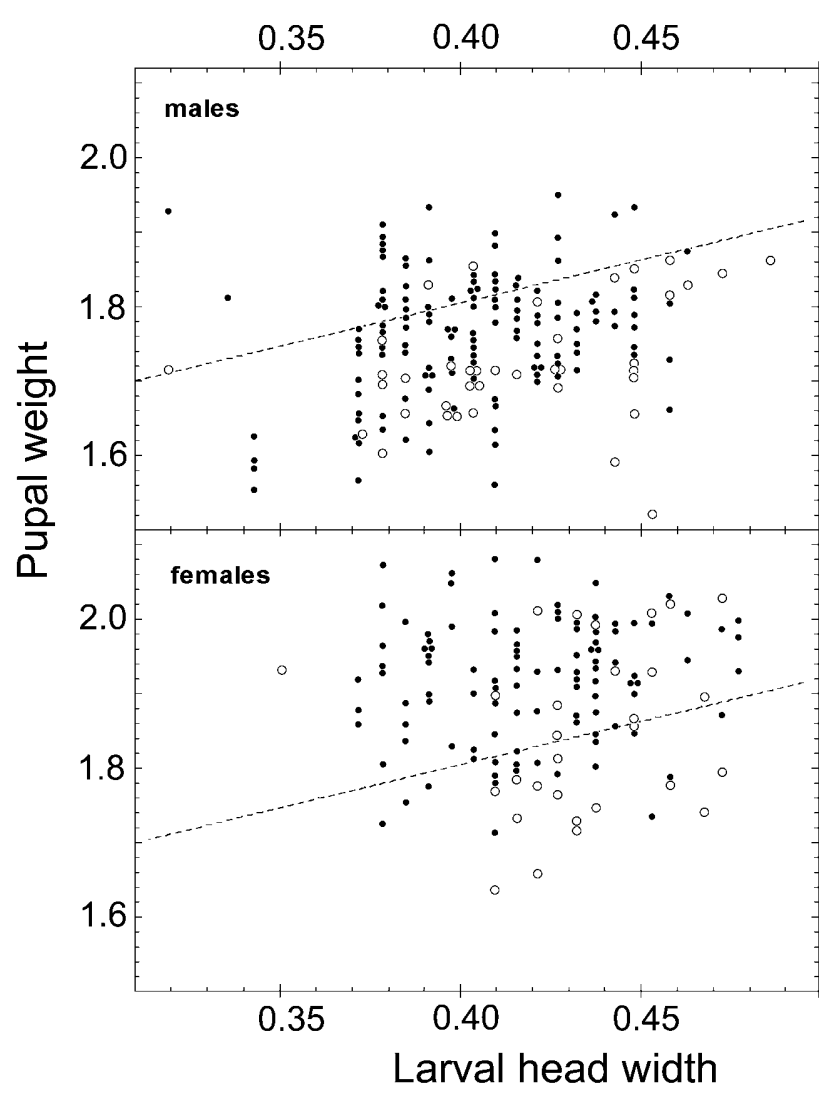

Fig. 4. Relationship between the head width of the last instar larva and pupal weight in males (above) and females (below). For both sexes, individuals with four larval instars are indicated by solid dots, and those with five instars by open circles. The dashed line shown in both plots represents the regression line fitted to the whole sample (males and females pooled): $\log$ $($ Pupal weight $)=0.64+0.71 \log ($ Larval head width $), r=0.29 \mathrm{~g}$ $\mathrm{P}<0.0001, \mathrm{n}=343$. The correlations for each sex and number of larval instars are: males (four instars), $\mathrm{r}=0.19, \mathrm{P}=0.016$; males (five instars), $\mathrm{r}=0.58, \mathrm{p}<0.0001$; females (four instars), $\mathrm{r}=0.08, \mathrm{P}=0.35$; females (five instars), $\mathrm{r}=0.20, \mathrm{P}=0.23$.

of larvae with five instars in photoperiods equal to or longer than $15 \mathrm{~L}: 9 \mathrm{D}$ vs. those shorter than 15L: 9D, Fig. $3: X^{2}=65.22, \mathrm{P}<0.0001$, d.f. $\left.=1\right)$. If the actual developmental pathway (i.e., diapause or direct development) is considered, its association with the number of larval instars is even stronger (comparison of the proportions of larvae with one extra instar in the direct developing and diapausing larval groups: $X^{2}=84.51, \mathrm{P}<0.0001$, d.f. $=1$, Fig. 3). In other words, the conditions inducing diapause also induced the 5-instar development pathway in some larvae, while five instars were very rarely recorded under conditions favouring direct development (Fig. 3). Overall, the number of larval instars was independent of sex: $X^{2}=$ $0.03, P=0.86$, d.f. $=1$ (incidentally, the sex ratio departed slightly from equality, $55 \%$ males: $45 \%$ females).

\section{Relationships between number of instars, head capsule width and pupal weight}

Pupal weight was correlated with last instar larval head width for the whole sample. This relationship was statisti-
TABLE 3. Tests for the effects of sex and type of larval development (direct or diapause) on pupal weight for all the larvae, based on log-transformed data. Nested ANCOVA analyses (last instar larval head width set as covariate) for, (a): Comparison between male and female pupal weights within each instar class (4 or 5). (b): Comparison between the pupal weights of direct developing and diapausing individuals (Development) within each sex. In both instances the last instar larval head width was set as covariate. Pupal weight was found to differ between sexes in each instar class, as well as between the types of development within each sex

\begin{tabular}{lccccl}
\hline \multicolumn{7}{l}{ Dependent variable $=$ pupal weight } \\
\hline (a) & SS & df & MS & F & \\
\hline Head width & 0.108 & 1 & 0.108 & 16.45 & $\mathrm{P}=0.0006$ \\
Sex & 0.803 & 1 & 0.803 & 122.36 & $\mathrm{P}<0.0001$ \\
Instars (sex) & 0.144 & 2 & 0.072 & 10.94 & $\mathrm{P}=0.0001$ \\
Error & 2.527 & 385 & 0.007 & & \\
\hline (b) & $\mathrm{SS}$ & $\mathrm{df}$ & $\mathrm{MS}$ & $\mathrm{F}$ & \\
\hline Sex & 1.783 & 1 & 1.783 & 283.9 & $\mathrm{P}<0.0001$ \\
Development (sex) & 0.314 & 2 & 0.157 & 25.0 & $\mathrm{P}<0.0001$ \\
Error & 2.425 & 386 & 0.006 & & \\
\hline
\end{tabular}

cally significant, but not strong (Fig. 4). More detailed inspection of the data revealed that the correlation is significant for males $(\mathrm{r}=0.249, \mathrm{P}=0.0002, \mathrm{n}=216)$, but not females $(\mathrm{r}=0.049, \mathrm{P}=0.52, \mathrm{n}=174)$. These trends were confirmed for each of the instar groups within each sex (Fig. 4). It was also evident that the ratio of pupal weight to larval head size was higher for female than male individuals. In spite of the within-group correlations described above, a comparison of the mean pupal weights and head sizes between instar groups for each sex (Fig.

TABLE 4. Tests of the effects of sex and of the number of instars on pupal weight within each sex, taking into account the general effect of last instar head width. The comparison is restricted to larvae that entered diapause. Above (a), comparison between the pupal weights of diapausing individuals with 4 or 5 instars (Instars) within each sex (nested ANCOVA, head width set as covariate). Below (b), test for planned comparison following the main results of (a); the effect tested is that pupal weights (relative to head width), fit the hypothesis: $\left(P W \mathrm{f}_{5}<\right.$ $P W \mathrm{f}_{4}$ and $\left.P W \mathrm{~m}_{5}>P W \mathrm{~m}_{4}\right)$, where $P W=$ pupal weight, $\mathrm{f}=$ female, $\mathrm{m}=$ male, and $4-5$ is the number of larval instars. The number of larval instars had a significant effect on pupal weight within each sex (a), and this effect differed as predicted by the above hypothesis (b): adding one instar resulted in comparatively heavier male pupae and lighter female pupae (both relative to last instar larval head size).

\begin{tabular}{lccccc}
\hline \multicolumn{6}{l}{ Dependent variable $=$ pupal weight } \\
\hline (a) & SS & df & MS & $\mathrm{F}$ & \\
\hline Head width & 0.094 & 1 & 0.094 & 14.245 & $\mathrm{P}=0.0002$ \\
Sex & 0.574 & 1 & 0.574 & 87.474 & $\mathrm{P}<0.0001$ \\
Instars (sex) & 0.052 & 2 & 0.026 & 3.996 & $\mathrm{P}=0.0201$ \\
Error & 1.169 & 178 & 0.007 & & \\
\hline (b) & $\mathrm{SS}$ & $\mathrm{df}$ & $\mathrm{MS}$ & $\mathrm{F}$ & \\
\hline Effect & 0.045 & 1 & 0.045 & 6.873 & $\mathrm{P}=0.0095$ \\
Error & 1.169 & 178 & 0.007 & & \\
\hline
\end{tabular}




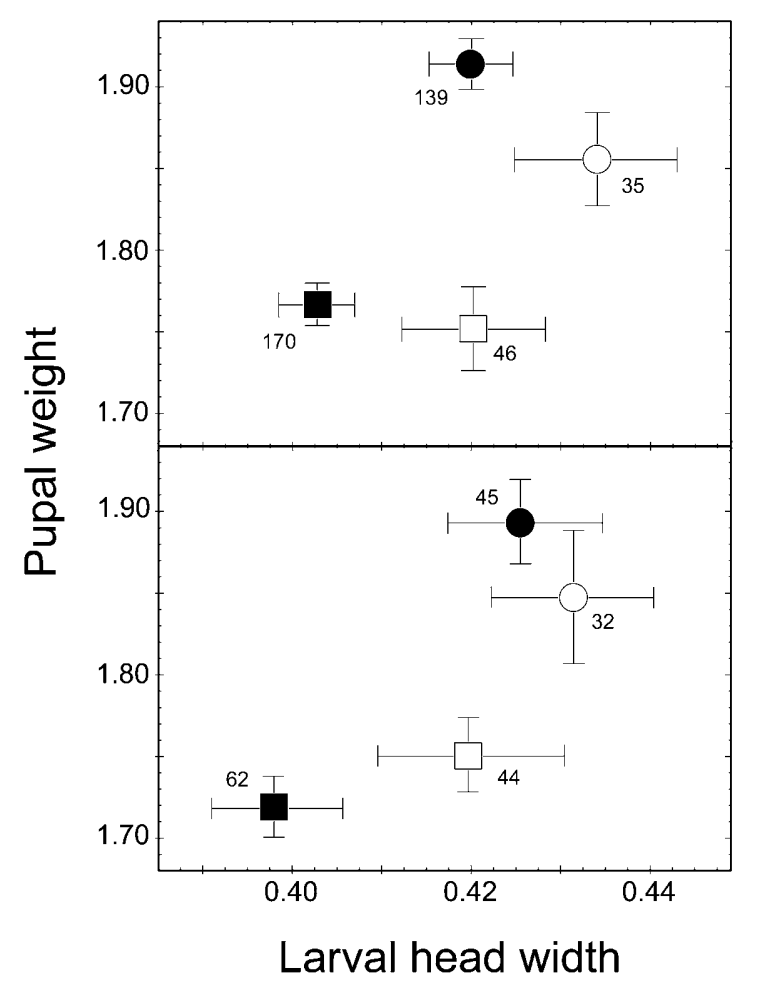

Fig. 5. Relationship between mean last instar larval head width and average pupal weight for males (squares) and females (circles) that underwent four (solid) and five (open) larval instars. Bars indicate $95 \%$ confidence limits for the mean and numbers sample sizes. Above, all individuals for which there were head measurements and pupal weights; below, only those individuals that entered larval diapause. All data were logarithmically transformed.

5a) suggested an overall negative relationship between these two variables (Table 3a). This resulted because directly developing individuals of both sexes were heavier than diapausing ones (Table 3b) and very few of the direct developing individuals moulted more than three times ( $2 \%$ at most, Fig. 3). A similar plot of the data of larvae of known sex that entered diapause suggested that, within these conditions, the males that had an additional instar (and hence larger heads) metamorphosed into heavier pupae, while the opposite was the case for females (Table 4; Fig. 5b). This is also the case when the data is grouped according to sex, number of instars, and rearing conditions (Fig. 6; nested ANCOVA: $\mathrm{F}_{1,174}=5.07$ $\mathrm{P}=0.026$ ).

\section{DISCUSSION AND CONCLUSIONS}

The results indicate that larval head width is not a reliable tool for identifying instar in this butterfly. It has to be stated, however, that the overlapping in the frequency distributions of the instar-specific head capsule widths was to some extent increased by combinating data from larvae reared under different conditions. If restricted to larvae reared under the same conditions and showing direct development, the four instars can usually be readily identified by eye. As formerly shown for a number of Lepidoptera and other insects, the variable number of

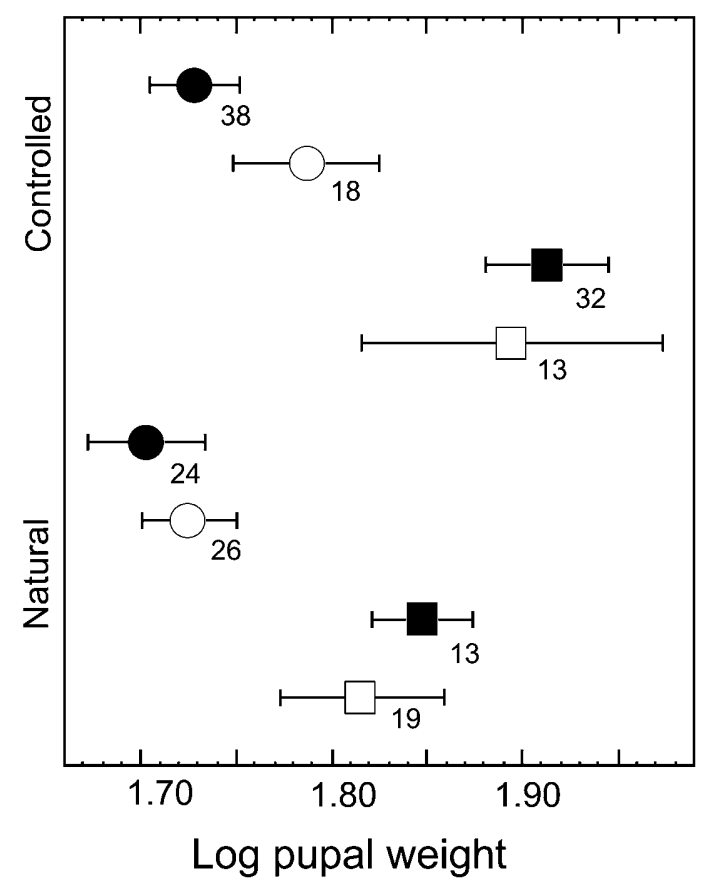

Fig. 6. Mean weights of pupae (log-transformed pupal weights) of diapausing individuals of $C$. pamphilus of both sexes and both instar goups (four and five instars), reared either under constant temperature and day length conditions or outdoors. Circles $=$ males, squares $=$ females, black $=$ four instars, open $=$ five instars. Bars indicate $95 \%$ confidence limits.

instars in C. pamphilus is not uncommon (further examples in Silver, 1958; Kishi, 1971; Schmidt et al., 1977; Daly, 1985; Weatherby \& Hart, 1986; Pershing et al., 1988). In C. pamphilus, however, an extra instar occurs in some of the larvae that undergo diapause when temperatures are mild. In these conditions the diapausing larvae continue to feed. The same explanation applies to larvae reared under seminatural conditions from eggs hatched in late summer in this study. They started to feed on potgrown fresh grass at a relatively early date compared to wild individuals, and hence had more time for growth (probably as much as one month: García-Barros, unpubl.). Similarly, they experienced decreasing latesummer photoperiods and the majority of them entered diapause.

The observations presented, including the correlations between the head widths of consecutive instars, support the idea that a fifth larval instar is a potential sub-routine of growth associated with diapause. Further, the option of an extra instar appears to be determined early in larval life, probably before the first moult. This mode of development is characterised by a comparatively low rate of larval size increase relative to instar number, with the mean larval sizes of successive instars following a regular progression. The "five-instar" diapausing pathway does not compensate for poor growth in early instars (because food plant quality was the same in all experiments), nor is it related to sex. Thus, it is tempting to speculate on its possible adaptive significance. From this point of view it is worth noting that the incidence of five larval instars 
was low and that the conditions promoting this growth pattern are unlikely to occur frequently throughout this insect's geographic range. Co-occurrence of short photoperiods inducing diapause and mild temperatures may predictably occur, however, in the South of Europe. The "five-instar" slow developing larvae are here hypothesized as a way of taking advantage of available resources (food plants and temperature) without abandoning larval diapause (as recorded for other insects: Danks, 1994). This makes sense in areas like the Mediterranean region, where the above conditions frequently occur in an unpredictable way during autumn. This is consistent with the fact that polymorphic insect life cycles are often associated with habitat unpredictability (Tauber \& Tauber, 1981 and references therein).

Adaptive explanations such as that proposed above rely on the assumption that some additional larval growth may enhance individual fitness. Since adding one instar resulted in larger last instar larvae, greater pupal weights (and hence larger adults) are to be expected for insects of both sexes. This was confirmed for males, but the reverse was the case for female pupae of the five-instar group. This relationship is difficult to explain without reference to development times or growth rates (e.g. Wiklund et al., 1991; Nylin, 1992). However, a purely size-based interpretation is pertinent, for we are dealing with the relationship between two estimates of size (i.e. larval head and pupal size) and two alternative adaptive explanations are possible. First, and assuming that larval ingestion and assimilation rates are similar for the larvae of both sexes, female larvae might invest proportionally more in larval tissues not destined for conversion into adult structures (e.g. a tougher cuticle or other features that could enhance winter larval survival). Second, post-diapause larval growth, which in nature means spring growth, presents different demands for the two sexes. Females accumulate a proportionally higher amount of fat, perhaps incurring costs in terms of investment in other body structures. This would make sense if the nutrient assimilation of the different larval instars differed, with the last instar contributing comparatively little to the reproductive reserves (as shown for other insects: Flanagin et al., 2000). Thus both adaptive and constraint-based hypotheses are possible. A closer investigation of the correlation between instar number and larval size, as well as between these and pupal or adult size, are needed for a more thorough interpretation of the observed pattern.

Similar observations from related taxa, or those with a comparable phenology in seasonal environments, would also be of interest. In fact, variation in the number of instars in circumstances similar to those described above may not be unusual. The author (García-Barros, 1988) observed a similar type of behaviour in hibernating larvae of the univoltine satyrine, Hipparchia alcyone (D. \& Schiff., 1775). These larvae were accidentally kept in mild temperature conditions during winter: some of the larvae went through a further (sixth) instar and metamorphosed into adults that were of a larger size than those that developed from their five-instar siblings. In a series of papers on the phenology of the satyrine Pararge aegeria (L., 1758) in Britain, Tilley (1993-1997) reports developmental polymorphism that mirrors that described in this study. In P. aegeria some of the hibernating larvae go through an extra instar although, unlike C. pamphilus, these individuals usually hibernate as pupae (Tilley, 1993, 1996). Even when there is evidence of an extra instar occurring in larvae exposed to short photoperiods (Tilley, 1997), the comparison with C. pamphilus is not straightforward: $P$. aegeria can hibernate as either a pupa or a larva and there is no data on adult or pupal sizes from those experiments. Further comparative studies on phenologically similar species with hibernating larvae in areas with a mild winter season, as well as on taxonomically allied Lepidoptera, are needed to fully determine the adaptive nature and possible phylogenetic origin of this reaction norm.

ACKNOWLEDGEMENTS. I thank T. Esperk and two anonymous reviewers for useful comments and advice on the literature concerning varying number of instars in Lepidoptera and other insects.

\section{REFERENCES}

DALY H.V. 1985: Insect morphometrics. Annu. Rev. Entomol. 30: 415-438.

DANKS H.V. 1994: Diversity and integration of life-cycle controls in insects. In Danks H.V. (ed.): Insect Life-Cycle Polymorphism. Theory, Evolution and Ecological Consequences for Seasonality and Diapause Control. Kluwer Academic Publishers, Dordrecht, pp. 5-40.

DYAR H.G. 1890: The number of molts of lepidopterous larvae. Psyche 5: 420-422.

FinK T.J. 1984: Errors in instar determination of mayflies (Ephemeroptera) and stoneflies (Plecoptera) using the simple frequency, Janetscheck, Cassie and Dyar's law method. Freshwat. Biol. 14: 347-365.

Flanagin V.L., HaAse S.P. \& Juliano S.J. 2000: Effects of growth rates on development to metamorphosis in the lubber grasshopper, Romalea microptera. Oecologia 125: 162-169.

Gaines J.C. \& CAmpBell F.L. 1935: Dyar's rule as related to the number of instars of the corn ear worm, Heliothis obsoleta Fab., collected in the field. Ann. Entomol. Soc. Am. 28: 445-461.

García-Barros E. 1988: Estudio Comparativo de la Biología y Morfología de Cuatro Especies de Hipparchia Fabricius (Lepidoptera, Satyridae). Ediciones Universidad Autónoma de Madrid, Madrid, 379 pp.

Gargiullo P.M. \& Berisford C.W. 1982: Number of instars of the pitch pine tip moth, Rhyacionia rigidana (Lepidoptera: Tortricidae: Olethreutinae). Can. Entomol. 114: 531-534.

Goettel M.S. \& Philogene B.J.R. 1979: Further studies on the biology of Pyrrharctia (Isia) isabella (Lepidoptera: Arctiidae). III. The relation between head capsule width and number of instars. Can. Entomol. 111: 323-326.

Kemp D.J. 2000: The basis of life-history plasticity in the tropical butterfly Hypolimnas bolina (L.) (Lepidoptera: Nymphalidae). Austr. J. Zool. 48: 67-78.

Kishi Y. 1971: Reconsideration of the method to measure the larval instars by the use of frequency distribution of headcapsule widths. Can. Entomol. 103: 1011-1015.

KuDRNA O. 2002: The distribution atlas of European butterflies. Oedippus 20: 1-342. 
NyLin S. 1992: Seasonal plasticity in life history traits: growth and development in Polygonia c-album (Lepidoptera: Nymphalidae). Biol. J. Linn. Soc. 47: 301-323.

NyLIN S. 1994: Seasonal plasticity and life-cycle adaptations in butterflies. In Danks H.V. (ed.): Insect Life-Cycle Polymorphism. Theory, Evolution and Ecological Consequences for Seasonality and Diapause Control. Kluwer Academic Publishers, Dordrecht, pp. 41-67.

Nylin S. \& GotThard K. 1998: Plasticity in life-history traits. Annu. Rev. Entomol. 43: 63-83.

Nylin S., Wiklund C., Wickman P.-O. \& García-Barros E. 1993: Absence of trade-offs between sexual dimorphism and early male emergence in a butterfly. Ecology 74: 1414-1427.

Pershing J.C. \& Linit N.J. 1988: Variation in number of instars of Monochamus carolinensis (Coleoptera: Cerambycidae). $J$. Kansas Entomol. Soc. 61: 370-378.

Roos P. 1978: Die Präimaginalstadien der Satyriden. 2. Coenonympha pamphilus Linné (Lep.: Satyridae). Entomol. Z. 88: 213-216.

Schmidt F.H., CAmpbell R.K. \& Trotter JR. S.J. 1977: Errors in determining instar numbers trough head capsule measurements of a lepidopteran. A laboratory study and critique. Ann. Entomol. Soc. Am. 70: 750-756.

Silver G.T. 1958: Studies on the silverspotted tigermoth, Halisidota argentata Pack. (Lepidoptera: Arctiidae), in British Columbia. Can. Entomol. 90: 65-80.

SOONTIËNS J. \& BINK F.A. 1997: Developmental response of Coenonympha pamphilus (Lepidoptera: Satyrinae) to differences in Nitrogen and water content of grasses. Proc. Exp. Appl. Entomol. 8: 29-36.

TAuber C.A. \& TAuber M.J. 1981: Insect seasonal cycles: genetics and evolution. Annu. Rev. Ecol. Syst. 12: 281-308.
TiLley R.J.D. 1993: The development of the speckled wood butterfly, Pararge aegeria (L.) (Lepidoptera: Satyridae), in Southern Britain. Entomol. Gaz. 44: 233-238.

TiLLEY R.J.D. 1996: The complex development of the speckled wood butterfly Pararge aegeria (L.) (Lepidoptera: Satyridae) in Southern Britain. Entomol. Gaz. 47: 1-7.

TILLEY R.J.D. 1997: The photoperiodic response in larvae of the speckled wood butterfly, Pararge aegeria (L.) (Lepidoptera: Satyridae), reared at $20^{\circ}$ C. Entomol. Gaz. 48: 209-218.

Weatherby J.C. \& HART E.R. 1986: Developmental polymorphism in Acleris minuta (Lepidoptera: Tortricidae). Environ. Entomol. 15: 258-262.

West-Eberhart M.J. 1989: Phenotypic plasticity and the origins of diversity. Annu. Rev. Ecol. Syst. 20: 249-278.

WickMan P.-O., WiKLUND C. \& Karlsson B. 1990: Comparative phenology of four satyrine butterflies inhabiting grasslands in Sweden. Holarct. Ecol. 13: 238-246.

WiKLUND C., NYLIN S. \& ForsBerg J. 1991: Sex-related variation in growth rate as a result for large size and protandry in a bivoltine butterfly (Pieris napi L.). Oikos 60: 241-250.

Wiklund C. \& Solbreck C. 1982: Adaptive versus incidental explanations for the occurrence of protandry in a butterfly, Leptidea sinapis L. Evolution 36: 56-62.

Wigglesworth V.B. 1972: The Principles of Insect Physiology. 7 th ed. Chapman \& Hall, London, 827 pp.

Yin C.-M. \& Chippendale G.M. 1974: Juvenile hormone and the induction of larval polymorphism and diapause of the southwestern corn borer, Diatrea grandiosella. J. Insect Physiol. 20: 1833-1847.

Zноu H.-Z. \& Topp W. 2000: Diapause and polyphenism of lifehistory of Lagria hirta. Entomol. Exp. Appl. 94: 201-210.

Received March 17, 2005; revised and accepted July 1, 2005 